\title{
American Pediatric Society John Howland Award 2002: Acceptance
}

\author{
HOWARD A. PEARSON \\ Yale University School of Medicine, New Haven, CT 06520-9064, U.S.A.
}

Thank you, Dr. Siegel, for your guided tour through my life. And thank you for being my friend since you arrived in New Haven as an intern 30 years ago and for being my strong right arm during my years as chairman at Yale.

When I wrote the Centennial History of the American Pediatric Society in 1988, I said that the Howland Awardees occupied a pantheon of American pediatrics. Joining this illustrious group is somewhat intimidating, but I accept the honor with gratitude. The Howland Medal is especially meaningful to me because it is awarded by pediatric colleagues and peers for what they consider to be distinguished service to pediatrics as a whole.

Following the example of other Howland Awardees, I'd like to acknowledge some mentors who shaped my career. The first of these was my 10th-grade Biology teacher, Mr. Guy Tucker. Guy Tucker was an extraordinary and charismatic teacher who engendered in me a love and wonder of science which has lasted to this day.

Dr. Thomas E. Cone, Jr., was a wise and gentle physician (Fig. 1). He was my role model for choosing pediatrics. Dr. Cone, who wrote the definitive text on the history of American pediatrics, inculcated in me a life-long appreciation of medical history.

Dr. Louis K. Diamond was the father of pediatric hematology (Fig. 2). Under Dr. Diamond, I learned about blood diseases and mastered blood morphology. He was a quintessential clinical investigator, and with him I first experienced the excitement of clinical research.

Early in my academic career, Dr. Waldo "Bill" Nelson invited me to become a contributing editor in hematology to the Journal of Pediatrics. On many later occasions, Dr. Nelson reminded me that he had "discovered" me, and it is certainly true that he gave me my first opportunity on the national scene.

Albert Szent-Gyorgyi once wrote, "Discovery consists of seeing what everybody has seen and thinking what nobody has thought."

In 1968, shortly after I came to New Haven, a previously well, 7-mo-old girl was brought to our emergency room, in extremis. She had been perfectly well until $8 \mathrm{~h}$ earlier, when

Received June 17, 2002; accepted July 24, 2002

Correspondence: Howard A. Pearson, M.D., Yale University School of Medicine, P.O. Box 208064, 333 Cedar Street, New Haven, CT 06520-9064, U.S.A.; e-mail: Howard.pearson@yale.edu

Accepted at the 2002 Pediatric Academic Societies Annual Meeting, Baltimore, Maryland, U.S.A.

DOI: 10.1203/01.PDR.0000052082.62196.55

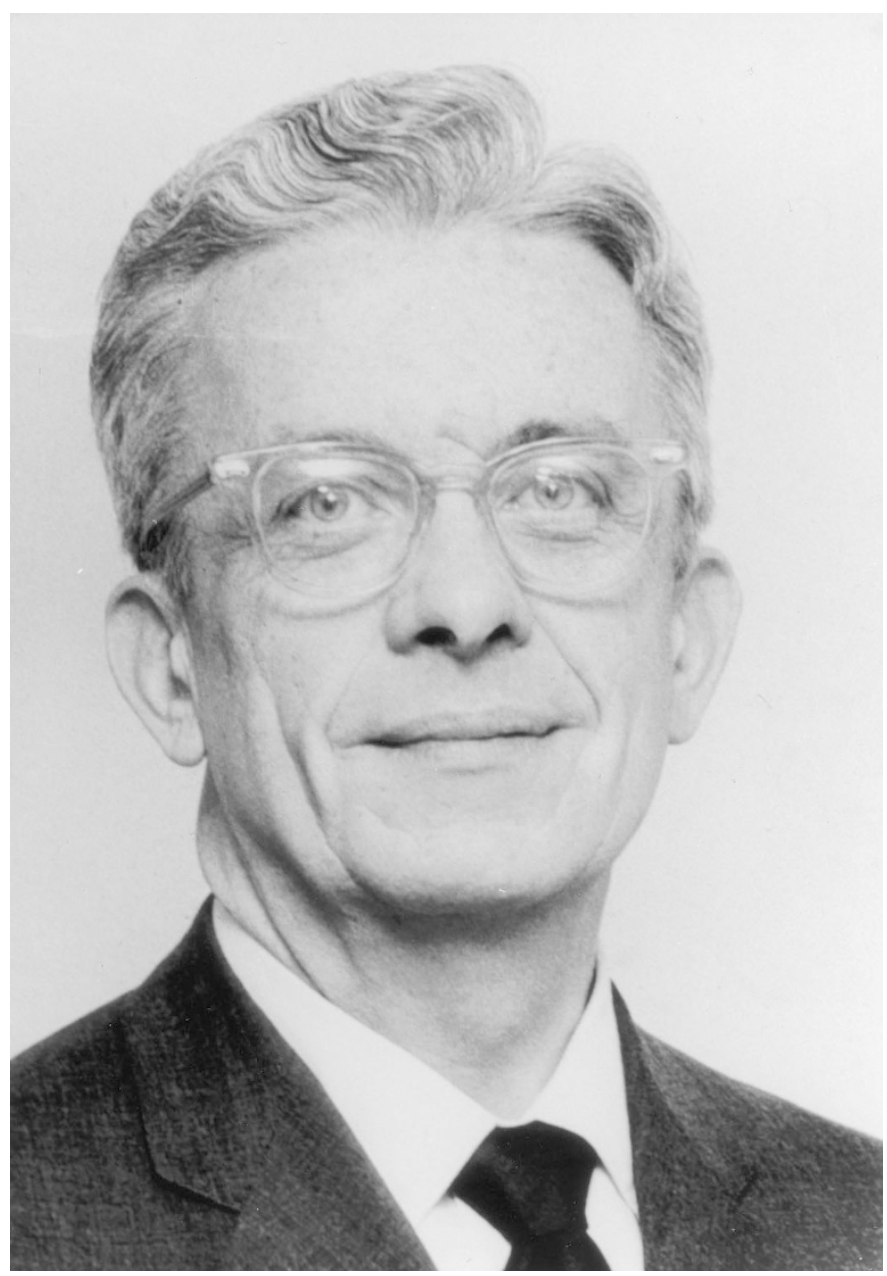

Figure 1. Dr. Thomas E. Cone, Jr., 1915-1998.

she developed progressive fever and then had a seizure. On admission to the emergency room, she was hyperpyrectic with a temperature of $105.8^{\circ} \mathrm{F}$ and was comatose. Her spleen was greatly enlarged. Despite valiant resuscitative efforts, she died. Type 14 pneumococci grew abundantly from her blood culture. Postmortem $\mathrm{Hb}$ electrophoresis showed that she had sickle cell anemia. The first clinical manifestation of sickle cell anemia in this child was death from an overwhelming infection.

Only a few months later, a 4-year-old boy with sickle cell anemia was brought to our hospital with severe pneumococcal sepsis, disseminated intravascular coagulation, shock, and a very enlarged spleen. Fortunately, he survived. 


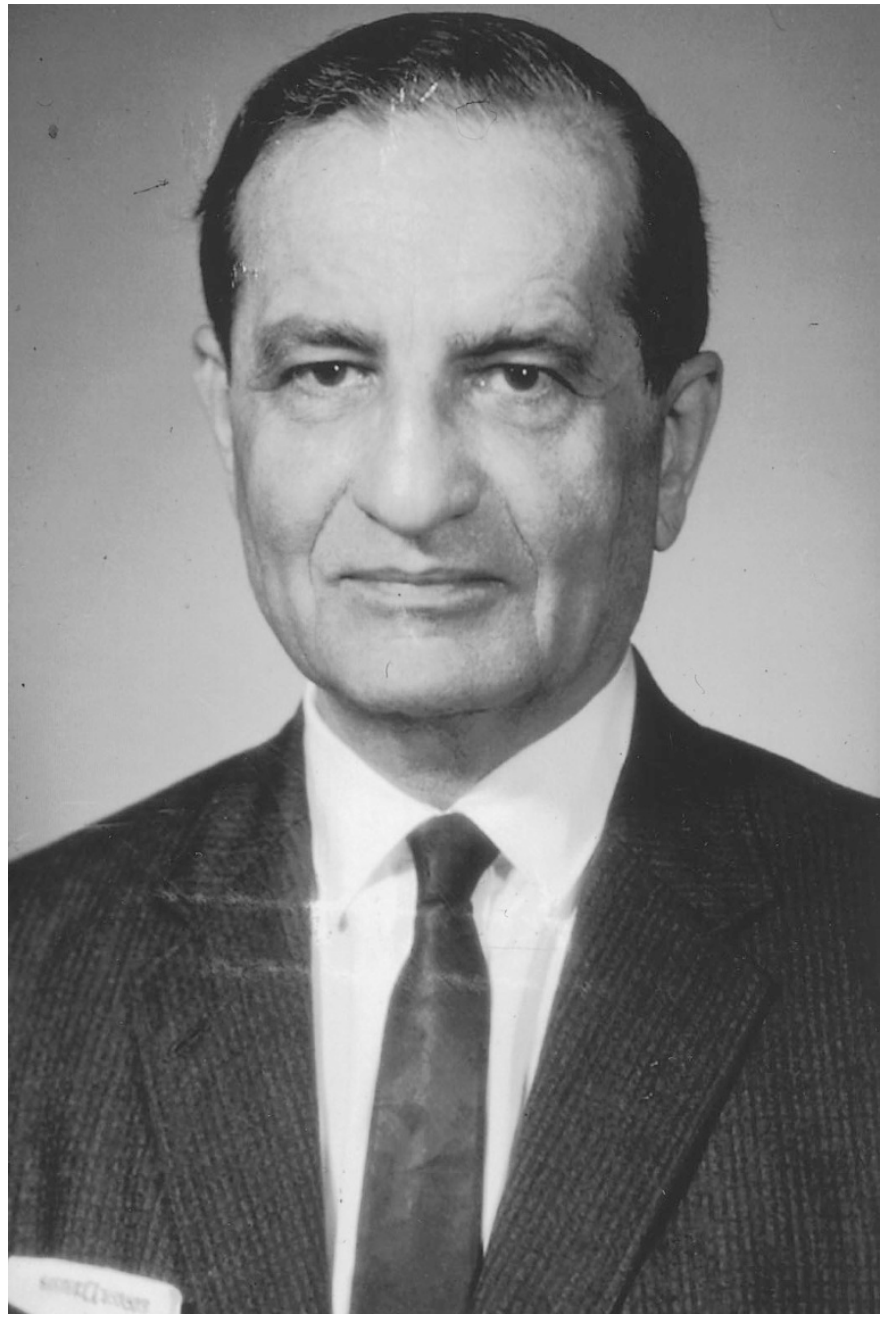

Figure 2. Dr. Louis K. Diamond, 1902-1996.

Patients with sickle cell anemia often develop fulminant pneumococcal infections in the first 6 years of life. The same clinical features of severe infections-young age, caused by encapsulated bacteria, chiefly pneumococci, clinically fulminant course with DIC and high mortality - are also seen in young children who have undergone surgical splenectomy.

The patient's blood smear showed the expected morphology of sickle cell anemia with target cells and irreversibly sickled cells, but in addition, many of his red blood cells contained Howell-Jolly bodies. Howell-Jolly bodies are nuclear remnants that are selectively and uniquely plucked from the red cells by the spleen, and their presence on the blood smear usually indicate asplenia. However, this child's spleen was greatly enlarged, and, in fact, splenomegaly is usually found in children with sickle cell anemia in their first few years of life.

We resolved the apparent paradoxes of severe, postsplenectomy-like infection and circulating Howell-Jolly bodies in this patient with an enlarged spleen by performing a technetium 99-sulfur colloid scan. This radiocolloid is taken up by reticuloendothelial organs, permitting their imaging. The radiocolloid scan of the patient showed normal hepatic uptake of the radiocolloid, but there was no splenic uptake.

We coined the term functional hyposplenia to describe defective reticuloendothelial function of the clinically enlarged spleens of young children with sickle cell anemia and contrasted this with the anatomic asplenia that occurs in the second decade of life because of autoinfarction. We postulated that functional hyposplenism was an important reason for their early susceptibility to overwhelming pneumococcal infections.

We showed that functional hyposplenia was not congenital but rather an acquired defect that develops in early life as the level of fetal $\mathrm{Hb}(\mathrm{Hb} \mathrm{F})$ decreases. We also showed that functional hyposplenia could be temporarily reversed by blood transfusions during the first five years of life-but not thereafter.

To avoid repeated radionuclide scans, we began to use a more simple diagnostic test. As red blood cells age in the circulation, they develop membrane vesicles. Using interference phase contrast microscopy, these vesicles appear as craters, "pits," or "pocks." Like Howell-Jolly bodies, the spleen removes these pocks. Patients with normal splenic function have fewer than $3.5 \%$ pocked $\mathrm{RBC}$, while asplenic patients have more than $12 \%$.

Using this technique, we studied the splenic function of more than 3,000 patients enrolled in the national Cooperative Study of Sickle Cell Diseases. There were characteristic developmental patterns of splenic dysfunction in the various sickle hemoglobinopathies. In $\mathrm{Hb} \mathrm{SS}$ disease and $\mathrm{Hb} \mathrm{S} \beta^{\circ}$ thalassemia, functional hyposplenia usually developed in the first year or two of life. In $\mathrm{Hb} \mathrm{S}-\beta^{+}$thalassemia, functional hyposplenia did not occur. In $\mathrm{Hb} \mathrm{S}-\mathrm{C}$ disease, an intermediate pattern was seen and functional hyposplenia did not usually occur in the first 5 years. These patterns correlated very well with the known clinical and hematological severity as well as the relative risk of infection in these sickle hemoglobinopathies.

In the 1960 s, as many as $30 \%$ of children with sickle cell anemia died from overwhelming infections in the first 5 years of life. We wanted to find a way to try to reduce this inordinate mortality. We reasoned that although we could not cure sickle cell anemia, we should be able to successfully treat early pneumococcal sepsis-but to do this, we needed to know which child was at risk. The only practical way to assure complete ascertainment of the $\mathrm{Hb}$ genotype in early life was to test all infants in the neonatal period while they were in the hospital. We also had to be able to differentiate Hb SS disease from the much more common sickle cell trait. In the 1960s, it was generally believed that neonatal, genotypic diagnosis of sickle cell hemoglobinopathies was difficult and unreliable, owing to the large amounts of $\mathrm{Hb} \mathrm{F}$ present at birth.

In 1970, we initiated our program for neonatal diagnosis. We used acid agar gel electrophoresis of cord blood $\mathrm{Hb}$. In this technique, $\mathrm{Hb} \mathrm{F}$ migrates out front in the vanguard of $\mathrm{Hbs} \mathrm{A}$ and $\mathrm{S}$ rather than occupying the confusing and obscuring intermediate position between that of $\mathrm{Hbs} \mathrm{A}$ and $\mathrm{S}$ seen on standard alkaline electrophoresis.

In our first 8 years, we diagnosed 19 newborn infants with sickle cell anemia. An important part of our program was that we provided comprehensive follow-up, especially seeing these children immediately if they developed fever. In 19 children who were diagnosed at birth and followed for at least 5 years, there were 179 episodes of fevers in excess of $38.2^{\circ} \mathrm{C}$. Six 
children, nearly one third of the group, had documented pneumococcal bacteremia. Historical controls suggested that about one third of these children should have died, but because of early diagnosis and treatment, we had no significant morbidity or mortality.

Our program for neonatal diagnosis and comprehensive follow-up was the first in the world and ultimately became a model for mass screening for hemoglobinopathies now being done in 44 American states. Neonatal diagnosis combined with pneumococcal immunization and prophylactic antibiotic therapy has markedly reduced mortality. In the 1950s and 1960s, the median survival in sickle cell anemia was only about 17 years. With the virtual elimination of the high early mortality from severe infections, the median life expectancy is now 47 years.

We were able to do spleen studies on patients with $\mathrm{Hb} \mathrm{SS}$ disease in the eastern province of Saudi Arabia. The sickle cell gene is very prevalent there, but the homozygous state is usually clinically mild because of persistent, high levels of fetal $\mathrm{Hb}$. Severe pneumococcal infections are unusual. Compared with age-matched American patients, two thirds of the Saudis had low numbers of pocked red blood cells, indicating normal splenic function, which would be protective against infection.

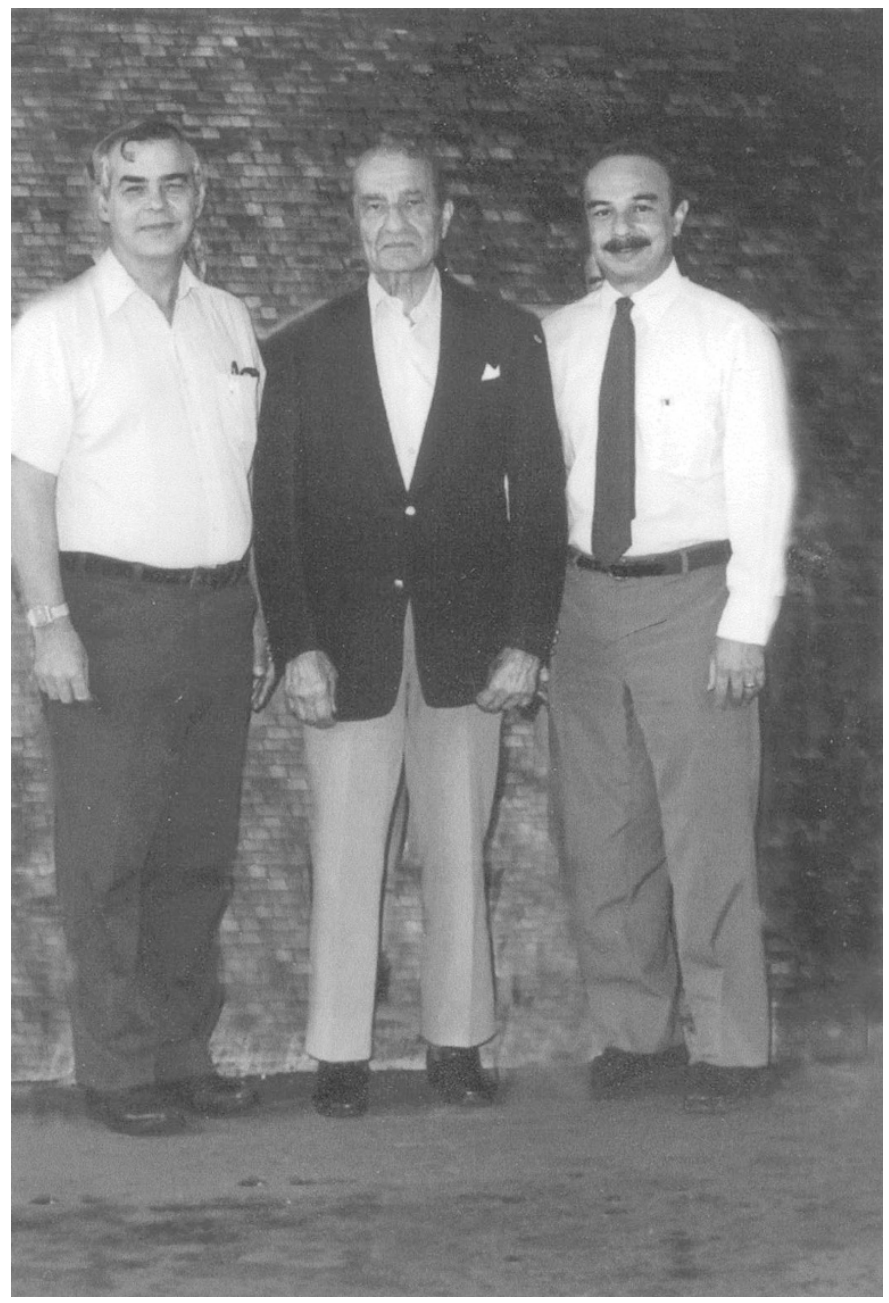

Figure 3. Drs. Howard A. Pearson, Louis K. Diamond, and Frank A. Oski.
An offshoot of these studies was our recognition that about half of children splenectomized for trauma have a return of splenic function as indicated by low numbers of pocked RBC when compared with children who were splenectomized under controlled conditions for hematologic or oncological indications. Technetium radiocolloid scans on several of these patient showed irregular patterns of uptake in the left upper quadrant. We postulated that this was due to splenosis - a regrowth of splenic tissue from spleen cells spilled into the peritoneum at the time of rupture of the splenic capsule.

This was during the Carter presidency, and my son Stephen, a medical student at the time, suggested that we should call this phenomenon the "born again spleen." Surprisingly, the New England Journal of Medicine accepted this title for our paper. Even austere medical journals sometimes have a sense of humor! Some years later, one of the patients died and at autopsy our clinical diagnosis of splenosis was confirmed pathologically by finding multiple nodules of splenic tissue on the peritoneum.

Early in my Hole in the Wall Gang Camp experience, I organized a special session for children with sickle cell diseases. I have studied and worked with this disease all of my career, but living with 100 sickle cell children $24 \mathrm{~h}$ a day for a whole week gave me some new insights and perspectives. In

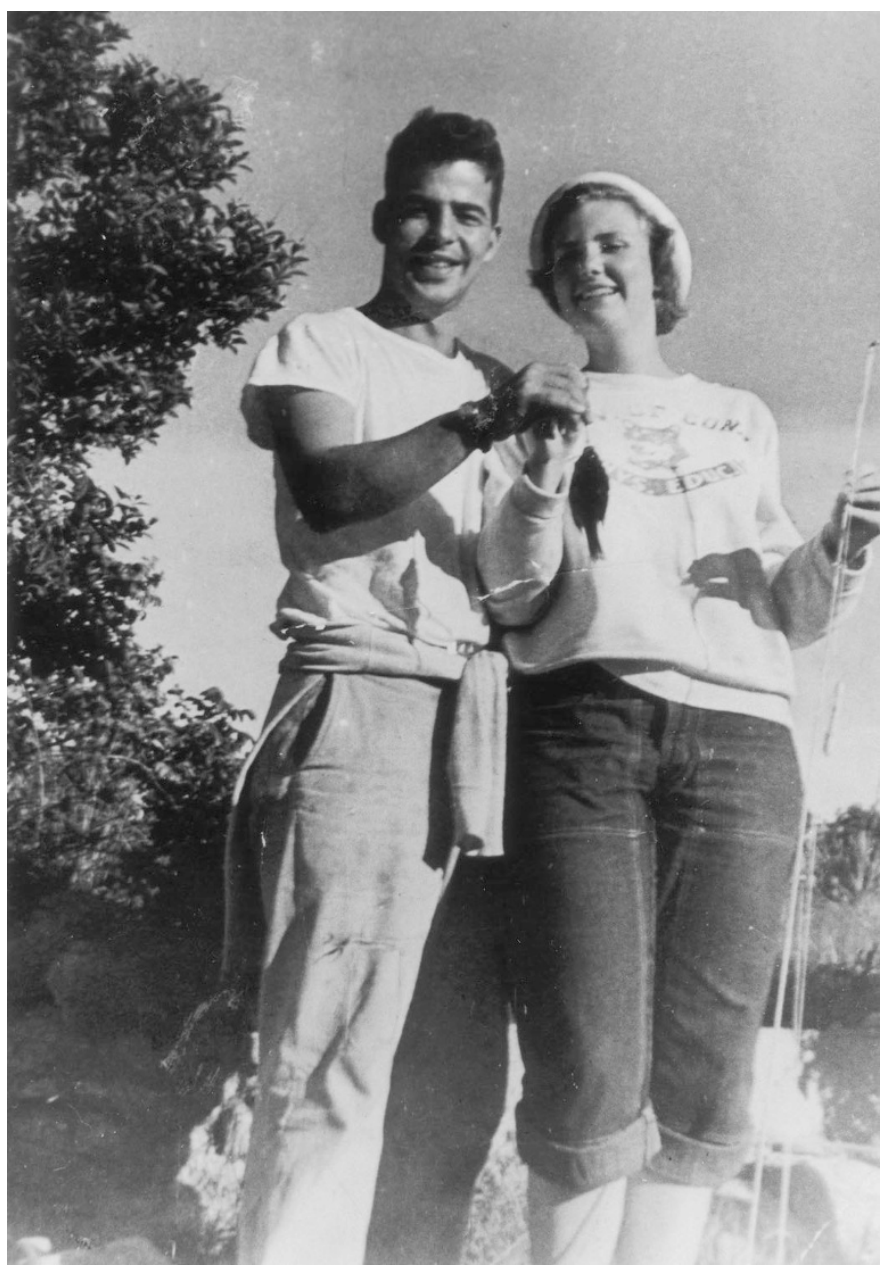

Figure 4. Howard A. Pearson and Anne S. Livingston, Cape Cod, MA, July 1949. 
the 1989 sickle cell session, $50 \%$ of the campers experienced a total of 111 painful episodes. Many were mild and easily controlled, but some required parenteral narcotics. I learned at Camp that sickle cell anemia is a far more uncomfortable, intermittently debilitating, and potentially demoralizing disease than I ever realized from the vantage of the teaching hospital.

I have taught that most pain crises do not have a precipitating antecedent. At Camp, a number of severe pain episodes began while the children were in or around our swimming pool, suggesting that whole body cooling might be responsible. In response to this, we cranked the water temperature of the pool up to $90^{\circ}$. At poolside, we set up an enclosed gazebo, with infrared heating lamps, which the counselors dubbed the "French Fryer." The children love it, and pool-related pain crises virtually disappeared.

As mentioned earlier, dating back to Dr. Cone, I have had a long-time fascination with pediatric history. While working in the Yale Medical School Historical Library, I came across medical student notes of the lectures of Dr. Eli Ives, who was a founder of the Yale Medical School in 1813. Between 1813 and 1852, Ives presented his course on the diseases of children to nearly 1,400 Yale medical students. This was the first formal course in pediatrics to be given in the United States. During this time, Ives held a Yale appointment as professor of the diseases of children. This makes him the country's first academic pediatrician, antedating giants such as Abraham Jacobi and Job Lewis Smith of New York by 50 years and Thomas Morgan Rotch in Boston by nearly a century.

I began by recognizing my mentors, and I'd like to finish by acknowledging a few other people. Dr. Frank Oski, shown here with Dr. Diamond and me, was a long-time friend (Fig. 3). We had many clinical and research interests in common. Frank undoubtedly would have received the Howland Award but for his untimely death. I'd like to think that my Howland Award acknowledges pediatric hematology and the kind of clinical research and teaching that Frank and I shared and loved.

I'd also like to thank the thousands of children that I have been privileged to treat, and hopefully to help, over the past 45 years. I am especially grateful to my own children. Despite their father's immersion in his work during their growing years, their accomplishments have made me very proud. And finally, my special thanks and love to my prize catch on Cape Cod more than 50 summers ago (Fig. 4). Anne, you have been and are the wind beneath my wings. 